\title{
El primer centenario de la muerte de Heredia
}

El día 7 de mayo del presente año, se conmemorará el centenario de la desaparición de José María Heredia, una de las más claras voces poéticas del continente americano.

Este centenario adquiere significación especial para nosotros, no sólo porque Heredia vivió en México la mayor y mejor parte de su vida, sino también porque aquí terminó sus días, y en suelo mexicano reposan sus despojos.

La historia de nuestro país influyó decisivamente en el curso de su existencia. Ningún escrito del poeta se discute más que su carta al general Tacón, solicitando en 1836 autorización para visitar a su madre en Cuba. En ella, el hombre que desde su primera juventud había luchado con valor por la independencia de su país, confiesa haberse equivocado. Este documento es incomprensible, si no se le vincula íntimamente con la historia nuestra.

"Las calamidades y miseria que estoy presenciando hace ocho años -escribe desde México a Tacón-, han modificado mucho mis opiniones, y hoy vería como un crimen cualquier tentativa para trasplantar a la feliz y optulenta Cuba, los males que afligen al continente americano".

Se ha censurado acremente a Heredia su retractación y se le acusa de insinceridad y carencia de patriotismo. Pero a medida que pasa el tiempo, esta carta aparece ante el juicio im- 
parcial, como la expresión sencilla y veraz del desencanto que en un hombre de sensibilidad particularmente afinada, habían producido las confusas tragedias de la historia independiente de nuestro país.

Recordemos con brevedad sus impresiones más salientes. Recién llegado a México en I825, escribió a su madre: "Vivo en un país regido por instituciones que se adaptan a mis sentimientos, y en que me estiman acaso más de lo que valgo".

E1 Presidente Victoria lo protegió generosamente y Heredia, que con veintidós años no cumplidos había desembarcado enfermo y en condiciones de debilidad física extrema, recuperó el vigor con rapidez.

Por eso escribía satisfecho a uno de sus familiares: "Mi librero va a abrir una lámina con mi linda cara para poner mi retrato al frente de las poesías americanas que van a imprimirse. Verás qué gordo estoy". Y en la misma carta hay una confidencia curiosísima: "Todos los días bebo pulque, y creo que a eso debo lo bien que me va, gracias a Dios. Aun creo que en volviendo a Cuba me ha de hacer falta".

Pronto pasaron, por desgracia, estos días felices. La paz de la República no pudo prolongarse mucho tiempo. Las divisiones internas fueron avivadas por visibles influjos extranjeros y levantamientos y revueltas hicieron de nuestro país un campo de batalla.

"No sé qué demonio enemigo turba la razón a los nuevos republicanos de América", escribía con amargura. Heredia en noviembre de 1828 . Sin embargo, tenía entonces todavía una esperanza: los desórdenes parecían de corta duración.

Mas, cuando se convenció de que la anarquía y el pillaje eran cada vez mayores, llegó a desesperar. Así, escribió en I833 hablando de la situación de México: "cada día me convenzo más de que esto no tiene atadero, y que la profunda inmoralidad e ignorancia de estas gentes les impedirán por un siglo o dos tener un gobierno, cualquiera que sea, que marche de un modo regular y seguro".

Dolorosos fueron estos tiempos para las naciones latinoamericanas, todas ellas prematuramente liberadas. E1. desastre ha- 
cía desfallecer a los mejores espíritus del continente. Ya Bolívar había escrito en Santa Marta: "América es el caos, quien la ha servido ha arado en el mar". Y años más tarde José María Luis Mora, otro hombre de excepción, escribía: "Casi me arrepiento de haber nacido mexicano".

La carta de Heredia al general Tacón no mancha la figura del Cantor del Niágara. Por lo contrario, demuestra que el poeta era capaz de auténtica honradez intelectual. Sólo los miopes de espíritu ignoraban que los abusos crecientes del militarismo y la corrupción administrativa, eran señales de peligrosa decadencia.

Heredia tuvo patriotismo y valor suficientes para expresar la verdad sin disfraces inútiles. Su retractación, es resultado inevitable de los dolorosos episodios que le tocó en suerte presenciar.

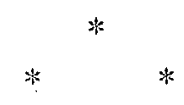

"La verdadera biografía de Heredia está aún por hacer y solamente puede escribirse en América", dijo don Marcelino Menéndez y Pelayo a fines del siglo pasado, y su afirmación tiene vigencia plena en nuestros días. Pero México puede enorgullecerse de que, en su territorio, hombres de la talla de Juan Clemente Zenea y José Martí hayan iniciado las investigaciones heredianas. Otros cubanos distinguidos los han seguido en el camino. García Vélez, Chacón y Calvo, Fernández de Castro, Larrondo y Maza y García Garófalo Mesa, han buceado en nuestros archivos con laboriosidad y acierto ejemplares.

$Y$ es satisfactorio hacer constar, por otra parte, que los investigadores nacionales han realizado en este punto trabajos de importancia. Don Nicolás Rangel, Mestre Ghigliazza, Núñez y Domínguez y don Manuel Toussaint, para no citar sino a los más eminentes, nos han permitido conocer pasajes fundamentales de la vida del poeta.

Por esto puede decirse, con entera justificación, que en México existe una tradición heredianista. $\mathrm{Y}$ de aquí la necesidad 
de que el centenario de la muerte del poeta no pase inadvertido.

Desde el año de r937 quedó constituído, por un grupo de estudiosos, el comité que deberá encargarse de organizar en nuestro país la conmemoración. Por sus méritos indiscutibles, la presidencia ha sido encomendada al sabio don Manuel Toussaint. Se cuenta ya con la cooperación de la Universidad $\mathrm{Na}$ cional, de la Secretaría de Relaciones Exteriores y del Departamento Autónomo de Prensa y Publicidad.

A partir del día del centenario, la Biblioteca Nacional expondrá en su vestíbulo una valiosa colección de impresos y manuscritos, heredianos. A los ejemplares rarísimos que el establecimiento conserva, se agregarán numerosas piezas procedentes de colecciones particulares. Esperamos que la exposición herediana de la Biblioteca Nacional, sea la más rica que en cualquier país pueda presentarse.

Además, el comité ha organizado un interesante ciclo de conferencias biográficas y críticas. $Y$ se ha hecho una selección de los más importantes trabajos periodísticos de Heredia, no recogidos en volumen, para editarlos. Todo esto nos parmite confiar en que el primer centenario de la muerte de don José María Heredia, será conmemorado en México dignamente.

Tuvo razón el poeta cuando escribió a su madre: "Me quedo en México, porque de no estar en Cuba, ¿dónde he de ir que más valga?"

Arturo Arnátz y Freg. 